\title{
Temporal trends of excessive consumption of soda and artificial juice in adults of a county of the Brazilian western Amazon (2007-20 I6)
}

\begin{abstract}
Due to the association between the consumption of sugar-sweetened beverage and various diseases and non-contagious demages, this consumption has been discouraged. The objective of this study was to analyze the temporal trend of excessive consumption of soda and artificial juice in adults of a county of the Brazilian Western Amazon. For this, a time series ecological study was carried out using the microdata from the Surveillance System of Risk Factors and Protection for Chronic Diseases by Telephone Inquiry (Vigitel). The trend analysis was performed using estimates from the Annual Percentage Change (APC) of the prevalence of excessive consumption of soda and general artificial juice and by sex in the period from 2007 to 2016 by means of Poisson regression in the software Join point. A total of 19,030 men and women aged 18 years and over were interviewed between 2007 and 2016. It was observed the downward trend in the period from 2010 to 2016 , with APC of -11.1 (95\% CI $=-15.9$ to -5.9$)$. When stratified by sex, the downward trend for both sexes was observed, in the male sex the CP was $-6.1(95 \% \mathrm{CI}=-9.7$ to -2.3$)$, and for females the APC was $-8.5(95 \%$ $\mathrm{CI}=-12.5$ to -4.4$)$.
\end{abstract}

Volume 8 Issue 5 - 2018

\begin{abstract}
Alanderson Alves Ramalho,' Flávia Santos Batista Dias,' Fernanda Andrade Martins'

Postgraduate Program in Collective Health, Federal University of Acre, Brazil
\end{abstract}

Correspondence: Alanderson Alves Ramalho, Postgraduate Program in Collective Health- Federal University of Acre, Campus Universitário-BR 364, Km 04 -Distrito industrial-CEP: 69.920-900, Rio Branco,Acre, Brazil, Email alandersonalves@hotmail.com

Received:September 23, 2018 | Published: September 27, 2018

\section{Introduction}

The Western dietary pattern consisting of large amounts of refined carbohydrates, sugar-sweetened beverage and unhealthy fats is among the leading causes of obesity and cardiometabolic diseases in the world. ${ }^{1}$ Health care costs attributable to obesity and overweight are over $\$ 600$ billion per year, $^{2}$ and the trend is to increase as the prevalence of overweight and obesity is increasing significantly. The World Health Organization projects that by 2025, about 2.3billion adults are overweight and more than 700million are obese. Between 2000 and 2013, the overall prevalence of overweight and obesity increased $25 \%$ among adults and 50\% among children. By 2013, more than 2 billion people were overweight, and of these, over 674 million were obese. ${ }^{3}$ In 2010 , it was estimated that overweight and obesity were responsible for causing 3.4 million deaths worldwide. ${ }^{4}$ Among the various factors associated with overweight and obesity, the consumption of sugarsweetened beverage deserves attention, because in the recent years, this consumption has increased in both high-income and low- and middle-income countries..$^{5-7}$ This increase is worrisome because besides the association with overweight, the consumption of sugarsweetened beverage is associated with cardiovascular diseases, some types of cancer, type 2 diabetes, quality and duration of sleep, nonalcoholic fatty liver disease. ${ }^{8-16}$ In Brazil, the National Food Survey observed that, in adults, the increase in the size of the portion of soft drinks was associated with overweight $(\mathrm{PR}=1.19,95 \%$ CI, $1.10-$ 1.27) regardless of age, sex, income and total energy ingestion. ${ }^{17}$ Data from the Surveillance System for Risk Factors and Protection for Chronic Diseases by Telephone Inquiry (Vigitel) of 2016, point out the city of Rio Branco as the Brazilian capital with higher prevalences of overweight and obesity in adults. Therefore, the objective of this study was to analyze the temporal trend of excessive consumption of soda and artificial juice in adults from Rio Branco, Western Brazilian Amazon, from 2007 to 2016.

\section{Materials and methods}

A time-series ecological study was carried out using the microdata from the Surveillance System of Risk Factors and Protection for Chronic Diseases by Telephone Inquiry (Vigitel) for the county of Rio Branco, Acre, from 2007 to 2016. Rio Branco, capital of the State of Acre, is located in the western Brazilian Amazon at 9 $9^{\circ} 8^{\prime} 29$ "south and at $67^{\circ} 48$ ' $36^{\prime}$ " west, at an altitude of 153 meters above the sea level. The capital has 348,354 inhabitants $(45.9 \%$ of the state's population), spread over an area of $9,962 \mathrm{~km}^{2}$ ( $6.5 \%$ of the territory of the State), with about $90 \%$ residing in the urban area. The sample consisted of 19,030 men and women aged 18 years or more between the years 2007 to 2016, having at least 1,500 participants each year. The prevalence of excessive consumption of soda and artificial juice was used as an outcome. The excessive consumption was defined as consumption on five or more days in the week, referring to the seven days prior to the survey. The trend analysis was performed with estimates of the Annual Percentage Change (APC) and the Average Annual Percentage Change (AAPC) of the prevalence of excessive consumption of soft drink and artificial juice and by sex between 2007 and 2016 by means of Poisson regression, using the Joinpoint statistical program (http:// surveillance.cancer.gov/joinpoint/). The technique uses the proportions to identify joinpoints over the period, capable of describing a significant change in the trend through APC.

The APC allows determining the magnitude of the change of the frequencies in a determined period of time. It assumes that the change occurs with a constant percentage in time, similar from year to year. As the biological phenomena do not always behave uniformly, the analysis of segments may better represent the phenomenon observed. In the APC concept of the segment, the join points correspond to k-1 segments. The summary measure of the various CPAs is the AAPC which corresponds to the average annual percentage change. In 
situations where only one APC comprises the entire period studied, the AAPC corresponds to APC. The tests of significance to choose the best model were based on the Monte Carlo permutation method, taking into account $p$ value $<0.05$. To minimize the effect of possible autocorrelations, the option "fit an autocorrelated errors model based on the data" was available in the software. Informed consent was obtained with the interviewees. The surveys were conducted by the Brazilian Ministry of Health and approved by the National Ethics Commission in Research.

\section{Results}

A total of 19,030 men and women aged 18 or over were interviewed between 2007 and 2016 (Table 1). The prevalence of excessive consumption of soda and artificial juice in 2007 was $32.9 \%$, and in 2016 it was $16.7 \%$ (variation of $-49.2 \%$ ). When stratified by sex, the prevalence in men was $36.5 \%$ in 2007 to $18.0 \%$ in $2016(-50.7 \%)$, and in women it was $29.6 \%$ in 2007 to $15.6 \%$ in $2016(-47.3 \%$, Table 2). Figure 1 shows the temporal trends of total prevalence and stratified by sex. When analyzing the trend of excessive consumption of soda and artificial juice (Figure 1) (Table 2), there is a downward trend in the period from 2010 to 2016 , with APC of -11.1 (95\% CI $=-15.9$ to $-5,9)$. When stratified by sex, there is a downward trend for the entire period studied in both sexes. For males the APC was $-6.1(95 \% \mathrm{CI}=$ -9.7 to -2.3$)$, and for the female PCA was $-8.5(95 \% \mathrm{CI}=-12.5 \mathrm{a}-4.4)$.

Table I Excessive consumption of soda and artificial juice (\%) by sex. Rio Branco - AC, 2007 to 2016

\begin{tabular}{lllllllll}
\hline & & \multicolumn{5}{c}{ Sex } \\
\cline { 3 - 8 } Year & n & $\%$ & Cl95\% & $\%$ & Cl95\% & $\%$ & Cl95\% \\
\cline { 3 - 8 } 2007 & 2010 & 32,9 & $29,2-36,7$ & 36,5 & $30,6-42,5$ & 29,6 & $25,0-34,3$ \\
\hline 2008 & 2012 & 29,5 & $24,8-34,3$ & 29,6 & $22,8-36,4$ & 29,5 & $22,9-36,1$ \\
2009 & 2023 & 32,1 & $27,8-36,5$ & 32,8 & $26,2-39,3$ & 31,5 & $25,8-37,3$ \\
2010 & 2016 & 35,5 & $30,2-40,9$ & 41,7 & $33,8-49,6$ & 29,9 & $23,1-36,6$ \\
2011 & 2002 & 30,3 & $25,7-34,9$ & 31,7 & $24,3-39,0$ & 29,1 & $23,4-34,8$ \\
2012 & 1662 & 29,0 & $25,7-32,3$ & 32,6 & $27,3-37,9$ & 25,7 & $21,6-29,8$ \\
2013 & 1971 & 24,6 & $21,5-27,6$ & 24,9 & $20,0-29,7$ & 24,3 & $20,4-28,2$ \\
2014 & 1517 & 18,6 & $14,9-22,2$ & 24,2 & $17,8-30,7$ & 13,4 & $10,0-16,8$ \\
2015 & 2011 & 21,1 & $18,0-24,2$ & 25,8 & $20,7-30,8$ & 16,8 & $13,1-20,4$ \\
2016 & 1806 & 16,7 & $14,6-18,9$ & 18,0 & $14,6-21,3$ & 15,6 & $12,8-18,5$ \\
\hline
\end{tabular}

Table 2 Distribution of the Annual Percentage Change (APC) of excessive consumption of soda and artificial juice by sex. Rio Branco - AC, 2007 to 2016

\begin{tabular}{lllllll}
\hline & \multicolumn{2}{c}{$\%(\mathrm{Cl} 95 \%)$} & & & & \\
\cline { 2 - 6 } & 2007 & 2016 & $\Delta \%$ & APC & Cl 95\% & Period \\
\hline Total & $32,9(29,2-36,7)$ & $16,7(14,6-18,9)$ & $-49,2$ & 3,6 & $-12,2$ a 22,3 & $2007-2010$ \\
& & & $-11,1$ & $-15,9$ a $-5,9$ & $2010-2016$
\end{tabular}

Sex

\begin{tabular}{lllllll} 
Male & $36,5(30,6-42,5)$ & $18,0(14,6-2 \mid, 3)$ & $-50,7$ & $-6,1$ & $-9,7$ a $-2,3$ & $2007-2016$ \\
Female & $29,6(25,0-34,3)$ & $15,6(12,8-18,5)$ & $-47,3$ & $-8,5$ & $-12,5$ a $-4,4$ & $2007-2016$ \\
\hline
\end{tabular}




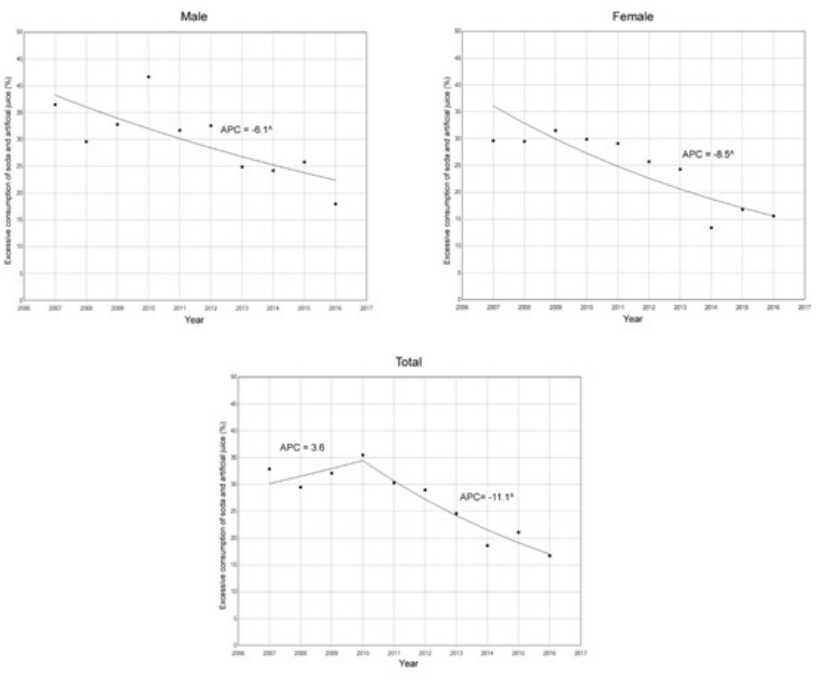

Figure I Temporal trend of the prevalence of excessive consumption of soda and artificial juice by sex. Rio Branco - AC, 2007 to 2016.

\section{Discussion}

In our study, there was an expressive decrease in the excessive consumption of soda and artificial juice in Rio Branco, Acre, for adults of both sexes. Despite this downward trend, the prevalence of soft drink consumption on five or more days in the week is still high. Due to the association between the consumption of soft drinks and various diseases and non-contagious demages, this consumption has been discouraged and several countries have adopted public health measures to maximize the reduction of consumption, and the increase in taxes on sugar-sweetened beverage, the most mentioned measure in the literature. ${ }^{18-22}$ Data from sugarcane tax countries show that such a policy is effective in reducing the sale and consumption of soft drinks. In Mexico, after approval of this type of tax in 2013, there was a $12 \%$ decrease in per capita purchases of sugar-sweetened beverage after one year and $9.7 \%$ in the second year. ${ }^{23,24}$ In addition, there was also an increase in the acquisition of healthier beverages. The data collected showed a $4 \%$ increase in purchases of bottled water after the first year and a $2.1 \%$ increase in purchases of untaxed beverages after the second year. ${ }^{23}$ In the first jurisdiction of the United States of America to approve tax on sweetened beverages in 2014, it was observed, after one year, a $9.6 \%$ drop in sales of taxed beverages and a $3.5 \%$ increase in untaxed beverages. ${ }^{25}$

While assessments of the impact of tax on health and economic indicators are underway, modeling studies have suggested that the effect will be largely beneficial. ${ }^{26,27} \mathrm{In}$ addition to reducing the consumption of sugar-sweetened beverage, the tax generates revenue that can contribute to programs that improve the health or socioeconomic development of the public. ${ }^{19}$ However, although the World Health Organization has recommended a $20 \%$ increase in the taxation of sugar-sweetened beverage, ${ }^{28}$ Brazil has not yet adopted this measure. The main limitation of our study is the impossibility of stratification by age, schooling, economic income and BMI. Our results are limited to stratification by sex. Besides that, some limitations regarding the methodology of the Vigitel survey should be considered in the interpretations of the results. Vigitel is based on self-reported information and may be subject to underestimation or overestimation. However, Vigitel's food and beverage consumption indicators were validated by Monteiro et al., ${ }^{29}$ which concluded good reproducibility and adequate validity for the consumption of soft drinks and artificial juices. Vigitel excludes individuals residing in households without fixed telephony coverage, which could result in sub-sampling. In order to minimize this bias, the effect of the Vigitel design was used. ${ }^{30}$

\section{Conclusion}

In our study, there was an expressive decrease in the excessive consumption of soda and artificial juice in Rio Branco, Acre, for adults of both sexes. Despite this downward trend, the prevalence of soft drink consumption on five or more days in the week is still high.

\section{Acknowledgements}

None.

\section{Conflict of interest}

The author declares that there is no conflict of interest.

\section{References}

1. Malik VS, Willett WC, Hu FB. Global obesity: trends, risk factors and policy implications. Nat Rev Endocrinol. 2013;9(1):13-27.

2. Credit Suisse. Sugar consumption at a crossroads. 2013.

3. Ng M, Fleming T, Robinson M, et al. Global, regional, and national prevalence of overweight and obesity in children and adults during 1980-2013: a systematic analysis for the Global Burden of Disease Study 2013. Lancet. 2014;384(9945):766-781.

4. Lim SS, Vos T, Flaxman AD, et al. A comparative risk assessment of burden of disease and injury attributable to 67 risk factors and risk factor clusters in 21 regions, 1990-2010: a systematic analysis for the Global Burden of Disease Study 2010. Lancet. 2012;380(9859):2224 2260.

5. Duffey KJ, Popkin BM. Shifts in Patterns and Consumption of Beverages between 1965 and 2002. Obesity (Silver Spring). 2007;15(11):2739-2747.

6. Barquera S, Hernandez-Barrera L, Tolentino ML, et al. Energy Intake from Beverages Is Increasing among Mexican Adolescents and Adults. J Nutr. 2008;138(12):2454-2461.

7. Popkin B. The world is fat: the fads, trends, policies, and products that are fattening the human race. New York: Avery; 2010.

8. Anjum I, Jaffery SS, Fayyaz M, et al. Sugar Beverages and Dietary Sodas Impact on Brain Health: A Mini Literature Review. Cureus. 2018.

9. Asgari-Taee F, Zerafati-Shoae N, Dehghani M, et al. Association of sugar sweetened beverages consumption with non-alcoholic fatty liver disease: a systematic review and meta-analysis. Eur J Nutr. 2018.

10. Hu FB, Malik VS. Sugar-sweetened beverages and risk of obesity and type 2 diabetes: Epidemiologic evidence. Physiol Behav. 2010;100(1):47-54.

11. Malik VS, Schulze MB, Hu FB. Intake of sugar-sweetened beverages and weight gain: a systematic review. Am J Clin Nutr. 2006;84(2):274 288.

12. Malik VS, Popkin BM, Bray GA, et al. Sugar-Sweetened Beverages, Obesity, Type 2 Diabetes Mellitus, and Cardiovascular Disease Risk. Circulation. 2010;121(11):1356-1364.

13. Malik VS, Popkin BM, Bray GA, et al. Sugar-Sweetened Beverages 
and Risk of Metabolic Syndrome and Type 2 Diabetes: A metaanalysis. Diabetes Care. 2010;33(11):2477-2483.

14. Miller PE, McKinnon RA, Krebs-Smith SM, et al. Sugar-Sweetened Beverage Consumption in the U.S.: Novel Assessment Methodology. Am J Prev Med. 2013;45(4):416-421

15. Greenwood DC, Threapleton DE, Evans CEL, et al. Association between sugar-sweetened and artificially sweetened soft drinks and type 2 diabetes: systematic review and dose-response meta-analysis of prospective studies. Br J Nutr. 2014;112(5):725-734.

16. Narain A, Kwok CS, Mamas MA. Soft drinks and sweetened beverages and the risk of cardiovascular disease and mortality: a systematic review and meta-analysis. Int J Clin Pract. 2016;70(10):791-805.

17. Bezerra IN, Alencar ES. Association between excess weight and beverage portion size consumed in Brazil. Rev Saúde Pública. 2018;52:21.

18. Blecher E, Liber AC, Drope JM, et al. Global Trends in the Affordability of Sugar-Sweetened Beverages, 1990-2016. Prev Chronic Dis. $2017 ; 14$.

19. Du M, Tugendhaft A, Erzse A, et al. Sugar-Sweetened Beverage Taxes: Industry Response and Tactics. Yale J Biol Med. 2018;91(2):185-190.

20. Lee BY, Ferguson MC, Hertenstein DL, et al. Simulating the Impact of Sugar-Sweetened Beverage Warning Labels in Three Cities. Am J Prev Med. 2018;54(2):197-204.

21. Zhen C, Finkelstein EA, Nonnemaker JM, et al. Predicting the Effects of Sugar-Sweetened Beverage Taxes on Food and Beverage Demand in a Large Demand System. Am J Agric Econ. 2014; 96(1):1-25.

22. Finkelstein EA, Zhen C, Nonnemaker J, et al. Impact of Targeted Beverage Taxes on Higher- and Lower-Income Households. Arch Intern Med. 2010;170(22):2028-2034.
23. Colchero MA, Popkin BM, Rivera JA, et al. Beverage purchases from stores in Mexico under the excise tax on sugar sweetened beverages: observational study. BMJ. 2016;352.

24. Colchero MA, Rivera-Dommarco J, Popkin BM, et al. In Mexico, Evidence Of Sustained Consumer Response Two Years After Implementing A Sugar-Sweetened Beverage Tax. Health Aff (Millwood). 2017;36(3):564-571.

25. Silver LD, Ng SW, Ryan-Ibarra S, et al. Changes in prices, sales, consumer spending, and beverage consumption one year after a tax on sugar-sweetened beverages in Berkeley, California, US: A before-andafter study. Plos Med. 2017;14(4):e1002283.

26. Manyema M, Veerman LJ, Chola L, et al. The Potential Impact of a $20 \%$ Tax on Sugar-Sweetened Beverages on Obesity in South African Adults: A Mathematical Model. Nishiura H, editor. PLoS One. 2014;9(8):e105287.

27. Sánchez-Romero LM, Penko J, Coxson PG, et al. Projected Impact of Mexico's Sugar-Sweetened Beverage Tax Policy on Diabetes and Cardiovascular Disease: A Modeling Study. PLOS Med. 2016;13(11):e1002158

28. World Health Organization (WHO). Taxes on sugary drinks: Why do it? 2016.

29. Monteiro CA, Moura EC, Jaime PC, et al. Validade de indicadores do consumo de alimentos e bebidas obtidos por inquérito telefônico. Rev Saúde Pública. 2008;42(4):582-589.

30. Bernal R, Silva NN da. Cobertura de linhas telefônicas residenciais e vícios potenciais em estudos epidemiológicos. Rev Saúde Pública. 2009;43(3):421-426. 